\title{
Informação, cognição e mediação: vertentes, contextos e pretextos
}

Aida Varela ${ }^{1}$

\section{Resumo}

Artigo que registra uma trajetória de estudos e pesquisas de 1998 a 2007, sobre o tema Informação, Cognição e Mediação em diferentes contextos, tais como comunidade (uso de estratégias para preservar a cidadania numa festa popular de São João), escola de Ensino Médio (integração de estratégia cognitiva inovadora ao currículo), escola de Ensino Superior (análise de necessidades de novas estratégias metodológicas para a leitura de textos complexos para se chegar à ciência) e de cotidiano profissional (tomada de consciência do uso de estratégias cognitivas quando em situações de atendimento ao usuário). Registra-se, com isso, o potencial de teorias de aprendizagem cognitivista e interacionista para acionar leituras de mundo, leitura de textos científicos e leitura de construção e desconstrução do conhecimento, subsidiando a autonomia do pensar, exigência dos novos avanços tecnológicos e científicos.

Palavras-chave: Informação. Cognição. Mediação. Leitura.

\begin{abstract}
This article registers a trajectory of studies and research from 1998 to 2007, on the subject Information, Cognition and Mediation in different contexts, such as community (use of strategies to preserve the citizenship in a popular party - São João), High School (integration of innovative cognitive strategy to the curriculum), University Studies (analysis of needs for new methodological strategies for the reading of complex texts to achieve science) and professional daily (awareness of the use of cognitive strategies when in situations of customer support). It is registered the potential of cognitive and interacionist learning theories to set in motion readings of world, reading of scientific texts and reading of construction and reconstruction of knowledge, subsidizing the autonomy of thinking, requirement of the new technological and scientific advances.
\end{abstract}

Key words: Information. Cognition. Mediation. Reading.

\footnotetext{
${ }^{1}$ Doutora em Ciência da Informação pela Universidade de Brasília, Brasil. Professora Adjunto do Instituto de Ciência da Informação da Universidade Federal da Bahia (UFBA), Brasil. varela@ufba.br.
} 


\section{Introdução}

O título e o tema deste artigo, elaborado para o II Workshop Internacional de Ciência da Informação, pretendem ser uma síntese de alguns anos de trabalho, um entrelaçamento das áreas de informação, cognição e mediação. Relendo, hoje, alguns trabalhos dessa trajetória confirmam-se as relações dos conceitos e as questões ali propostas à reflexão. Continuam atuais e grande parte dos problemas ali apontados principalmente de compreensão e apreensão da informação, ainda não estão resolvidos. O que se pretende fazer é a retomada destes conceitos e problemas, buscando identificar sua evolução, ao longo dos últimos anos, em um movimento progressivo, numa proposta de indissociabilidade da informação, cognição e mediação.

A qualidade da educação exige a participação engajada de cidadãos na própria construção da qualidade que se almeja. A qualidade não existe a priori, ela precisa ser negociada e construída, ela terá pesos e sentidos diferentes em cada contexto. Os espaços precisam ser intencionalmente alargados, flexibilizados e planejados para adensar à aprendizagem. Para exemplificar esforços de busca de qualidade apresentaremos as experiências a seguir.

\section{Informação e construção da cidadania}

Relata-se uma síntese da dissertação de mestrado defendida em 1999, no Programa de Pós-graduação em Ciência da Informação do Departamento de Ciência da Informação e Documentação da Universidade de Brasília (PPGCInf/CID/UNB), desenvolvida na Escola de Serviço Público - FUNDESP.

A FUNDESP era, na época desta pesquisa, uma fundação que vinculada à Secretaria da Administração - SAEB, assumia as características de uma Escola de Governo, tendo como finalidade viabilizar e executar a política de formação e capacitação de Recursos Humanos para o Serviço Público Estadual, como a responsabilidade de administrar o Programa Permanente de Capacitação do Servidor Público, criado através da Lei 6.354/91.

Entre as ações efetivadas pela FUNDESP, instituição administradora de um Programa Permanente de Capacitação, planejou-se e implementou-se, na linha de Desenvolvimento Humano na Administração Pública, o Programa Segurança Pública Cidadã, 
tendo, como fundamento precípuo, $\mathrm{o}$ atendimento às necessidades de segurança da comunidade, buscando fazer com que o policial militar resignificasse sua prática de cidadania, considerando as figuras do cidadão policial e do cidadão cliente.

O projeto de pesquisa Informação e Construção da Cidadania foi desenvolvido na Primeira Companhia Independente da Polícia Militar de Senhor do Bonfim, município da Bahia, durante uma festa popular - o São João - e objetivou demonstrar que a informação contextualizada, transferida por suporte metodológico adequado a uma clientela adulta, provoca mudanças individuais e transformações sociais.

Por meio de uma proposta pedagógica interativa construtivista, desenvolveu-se uma experiência de disseminação da informação e leitura continuada de contexto como pretexto para a observância da dinâmica de fatos vivenciados, registrados e analisados por protagonistas (policiais militares), orientados por uma equipe multidisciplinar para perceber, compreender, analisar redes, enredos, símbolos e refletir sobre o fazer profissional e sobre o "eu" diante de um mundo uno, somatório da objetivação e da subjetivação.

As atividades representaram uma alternativa para enfrentar o desafio de elevar a qualidade dos serviços de segurança, aliando informação/conhecimento, qualificação profissional e efetivação da cidadania. Constituiu-se objeto de estudo avaliar a mudança de comportamento gerado uma disseminação e transferência de informação específica e contextualizada, inovando estratégias baseadas em princípios construtivistas, partindo de dois pressupostos: existe um relacionamento entre a tecnologia, a transferência e a adoção de metodologias em determinada realidade, gerando produção de conhecimento; existe uma limitação contextual para a absorção da informação e esse processo de absorção somente ocorrerá se a metodologia adotada for aceita pelos sujeitos desse contexto.

O processo ação-pesquisa-ação atribuiu o papel de pesquisador ao aluno policial que construía o seu conhecimento à medida que desenvolvia as atividades de relatos de experiência, integrando o cognitivo, o afetivo e o psicomotor, interagindo com o outro, com a cultura, com o fazer cotidiano.

O principal alvo do modelo de gestão - Polícia Cidadã -, pretendido pela Polícia Militar que norteou os objetivos desta proposta, foi a interação do policial (prestador de serviços) e do cidadão (cliente), promovida a partir de mudanças no modo de agir da polícia, num trabalho de parceria em termos de segurança pública, com ênfase no aspecto preventivo.

O tema cidadania foi abordado segundo várias vertentes: direito, dever, participação, autonomia, crítica/criação, conquista, poder, tutela, assistência, ausência de cidadania, problema da pobreza, aumento da violência, situação do Brasil diante do quadro dos excluídos 
de um mercado de trabalho, neoliberalismo, relação violência e serviços de segurança, importância da informação e da educação na mudança civil e nos serviços de segurança pública - Polícia Militar e a preservação da cidadania.

O suporte conceitual do trabalho enfocou a informação como fator de desenvolvimento social, gerada por meio do esforço humano de entender, interpretar e comunicar a realidade. $\mathrm{O}$ campo relevante da transferência da informação foi enfocado como ferramenta para o desenvolvimento, para a distribuição/socialização da informação - fator importante para a construção do conhecimento.

A metodologia selecionada - ação-pesquisa-ação - concretizou-se à medida que as informações eram coletadas pelos policiais militares, por meio de entrevistas, questionários e observações que apresentavam diferentes roteiros de acordo com os objetivos específicos e as situações encontradas, exploravam-se idéias gerais sobre a comunidade, o fazer profissional e sentimentos. Para acompanhamento e avaliação dos resultados recriou-se a taxionomia de Bloom, domínio cognitivo e afetivo, integrado a categorias do processo de formação do indivíduo de Duarte e à "pirâmide informacional" de Urdaneta, como se demonstra na figura a seguir:

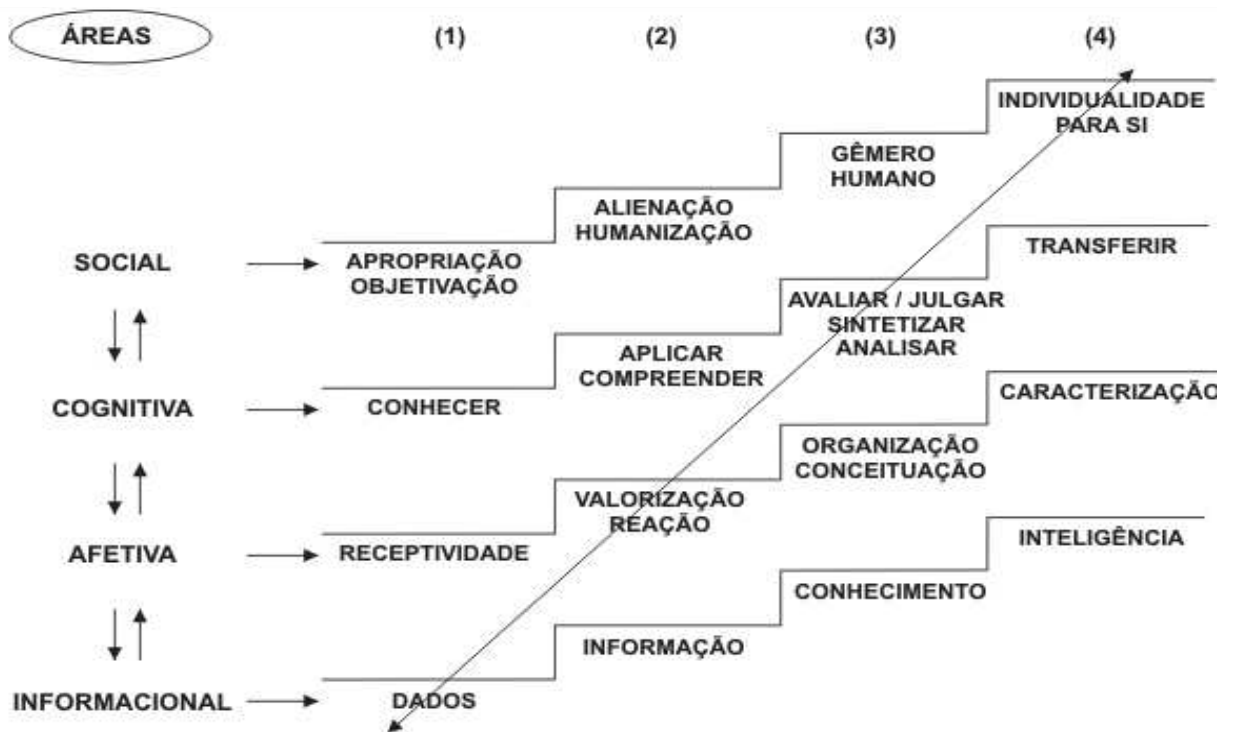

Figura 1. Transferência da Informação - níveis 1,2,3 e 4 (Parâmetros de acompanhamento e avaliação de transferência da informação) (URDANETA, 1992; BLOOM, 1974-1979; DUARTE, 1993).

A área cognitiva variou da simples evocação de material até maneiras altamente originais e criadoras de combinar e sintetizar novas idéias e materiais na seguinte gradação: conhecer, compreender, aplicar, analisar, sintetizar e avaliar. A área afetiva integrou as 
mudanças esperadas em interesses, atitudes, valores e apreciações, na seguinte gradação: receptividade, reação, valorização, organização e caracterização. As categorias de formação do indivíduo integraram: objetivação e apropriação, humanização e alienação, gênero humano e individualidade para si. A pirâmide informacional partiu de uma distinção funcional e gradativa de dados, informação, conhecimento e inteligência.

Assim, desde o momento em que se iniciou o processo de levantamento de dados sobre o cotidiano laboral dos policiais militares, descrevendo sua visão sobre o município, seu trabalho, suas dificuldades, como ele se vê, como ele vê o outro e o seu contexto, foram-se apreendendo os fatos observados: o fato e o ambiente; o fato, o ambiente e "eu"; os sentimentos confortáveis e desconfortáveis ao presenciar determinados fatos e o estabelecimento de juízos de valor. De maneira gradativa foi-se analisando a evolução cognitiva e afetiva dos policiais que participavam da experiência. Integravam-se idéias associadas às práticas relatadas; o trabalho interpretativo ia se processando à medida que as informações se encadeavam, formando um tecido mais amplo da realidade.

Delimitaram-se dois momentos neste estudo: "O Sair, O Ver e O Sentir" e "Sentir, Pensar e Agir". No primeiro momento "O sair" significou locomoção do policial-aluno em busca de dados. "O ver" significou a busca dos melhores, dentre vários, ângulos para ver e olhar, aguçando a atenção e a percepção. "O sentir" significou a compreensão da influência recíproca do contexto e ações observadas. A partir do sair e ver, dados da realidade foram percebidos (informacional) e apreendidos enquanto conhecimento (cognitivo) na medida de sua receptividade (afetivo) que resultou na apropriação da realidade (social).

A atividade "o sair, o ver e o sentir" foi reforçada, na sua construção, com análise e comentários a respeito do que foi coletado e complementado com textos sobre comunidade, sociedade, cidadania e gestão contemporânea.

A evolução do processo de coleta de dados e a delimitação do tema Serviços de Segurança e Cidadania provocaram novo momento no estudo - "Sentir, Pensar e Agir". Discutiam-se ações de segurança e o comportamento das pessoas durante as festas populares: comportamentos individuais e em multidão, os vários papéis e funções das pessoas durante o cotidiano, as várias visões sobre cidadania, violência, enfim, debatiam-se os problemas que "pipocam" quando as pessoas se sentem em estado de catarse, em lugares públicos, dançando, bebendo, passeando, com vários objetivos e interesses, focalizando, também, as redes de pessoas, negócios, instituições, serviços, dentre outras.

Como produto deste momento planos de intervenção, elaborados pelos participantes, representaram a fase de transferência de aprendizagem, correspondendo à generalização, à 
recuperação das informações. Os planos de intervenção e as peças teatrais exigiram ações mentais complexas de análise, síntese e avaliação, tornando-se necessário, por parte dos policiais militares, abstrações para demonstrar o uso do conhecimento, análise de elementos, relações e princípios organizacionais e geração de comunicações singulares.

Concluiu-se que: a realidade é produto de um processo de aproximações sucessivas entre o mundo subjetivo e o mundo objetivo, e que à medida em que as pessoas fazem registros (icônicos, simbólicos ou signos), representam fatos, conceitos ou instruções; quando existe no indivíduo uma receptividade sobre o observado sua atenção se concentrará e o filtro perceptual se abrirá para a ação de conhecer, iniciando-se um processo de objetivação, apropriação; à medida que os dados vão adquirindo significado - informação - em razão de uma reação positiva do indivíduo, a categoria de valor também aflora, facilitando o processo de aquisição do conhecimento e consequentemente a aplicação do mesmo; o conhecimento, a depender do modelo de racionalidade escolhida (visão total ou fragmentada da realidade) contribui para a humanização/alienação do indivíduo transferido; a transferência de informação, num fluxo sempre crescente, através de um suporte comunicacional dialógico, vai exigindo construções mentais mais complexas de assimilação e acomodação das informações/conhecimento, evoluindo, na mesma medida, para a construção da cidadania que não deve ser tutelada, nem assistida e, sim, uma cidadania emancipatória - cada um, na sua individualidade construída no coletivo, aprende a aprender.

\section{Informação e autonomia: a mediação segundo feuerstein}

Ainda tomando como base a temática Informação, Cognição e Mediação, apresentou-se a Tese de Doutorado "Informação e Autonomia: a mediação segundo Feuerstein”, defendida em 2003 no Programa de Pós-graduação em Ciência da Informação do Departamento de Ciência da Informação e Documentação da Universidade de Brasília (PPGCInf/CID/UNB). A tese foi ancorada em estudos diagnósticos educacionais, amplamente divulgados a respeito do grau de compreensão e interpretação dos leitores em todo o mundo, principalmente daqueles que freqüentam escolas da rede pública, conforme se pode verificar, nos relatórios do Exame Nacional do Ensino Médio (ENEM), do Sistema Nacional de Avaliação da Educação Básica (Saeb), do Instituto Nacional de Pesquisas Educacionais Anísio Teixeira (INEP/MEC), do Programa Internacional de Avaliação de Estudantes (PISA), 
dos Estudos e Pesquisas Acadêmicas em Educação e Leitura, entre outros, ainda não se alcançavam patamares adequados e congruentes com o momento histórico em que estamos vivendo.

A análise dos resultados da avaliação externa de desempenho levada a efeito pelas várias instituições de pesquisa registravam que os alunos da $8^{\text {a }}$ série do Ensino Fundamental, futuros alunos do Ensino Médio, apresentavam, as seguintes dificuldades:

1. Língua Portuguesa: fazer inferências globais com relação ao texto como um todo; fazer inferências locais com relação ao sentido de uma palavra; depreender de uma informação explícita outra informação implícita; estabelecer relações entre informações no próprio texto ou com outros textos, entre outras.

2. Matemática: efetuar cálculos com números racionais na forma decimal e fracionária; estabelecer relações de interdependência das variáveis de duas grandezas direta ou inversamente proporcionais; analisar informações apresentadas em tabelas ou gráficos; calcular medidas de figuras geométricas; pouca familiaridade com a linguagem matemática; resolver situações-problema, entre outras.

Para responder a esses anseios, o governo da Bahia, de 1999 a 2006, em seu programa Educar para Vencer, adotou, como uma das estratégias, o Programa de Enriquecimento Instrumental (PEI), com vistas à melhoria da aprendizagem de jovens do Ensino Médio, com o apoio da Agência Credennciada pelo ICELP/Israel, concebeu, implantou e coordenou os trabalhos de formação, formação continuada e pesquisa na implementação do PEI no Ensino Médio.

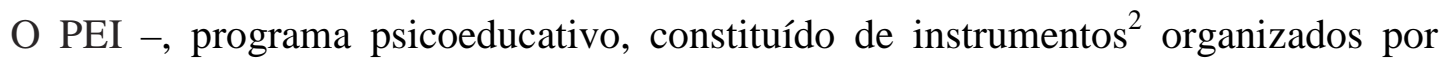
Reuven Feuerstein ${ }^{3}$ como um sistema aplicativo da Teoria da Modificabilidade Cognitiva

\footnotetext{
${ }^{2}$ Instrumentos do PEI - Com mais de 300 páginas contendo problemas e atividades distribuídos em 14 unidades de trabalho, os Instrumentos do PEI, estratégia de intervenção psicoeducativa, priorizam o desenvolvimento de funções cognitivas, permitindo a aquisição de numerosos pré-requisitos de aprendizagem. ${ }^{3}$ Reuven Feuerstein, nascido na Romênia, em 1921, estudou Psicologia e Pedagogia em Bucareste. Algum tempo depois, prestou exames de Licenciatura em Jerusalém. Estudou, também, em Genebra, Suíça (quando trabalhou com André Rey e Piaget), e na Universidade de Sorbonne, Paris. Feuerstein completou seus estudos em 1952 com Diploma em Psicologia Geral e Clínica, em Genebra, e, em 1970, com o Doutorado (Ph.D.) em Psicologia do Desenvolvimento na Universidade de Sorbonne, Paris. Suas principais áreas de estudo foram Psicologia do Desenvolvimento, Clínica e Cognitiva. Desde 1964, ele é Diretor do Instituto de Pesquisas Hadassah-Wizo-Canada, em Jerusalém. Feuerstein tem ensinado em diferentes universidades na condição de professor convidado. A partir de 1970, atuou como professor titular da Universidade Bar Ilan, em Ramat Gan, Israel e Professor Adjunto da Universidade de Vanderbilt, em Nashivile, USA. Feuerstein reside, atualmente, em Jerusalém, Israel. (BEYER, 1996).
} 
Estrutural - $\mathrm{TMCE}^{4}$-, que desenvolve, mediante a Experiência de Aprendizagem Mediada $\mathrm{EAM}^{5}$-, funções cognitivas e operações mentais e reúne características que asseguram uma autonomia de pensamento à medida que se desenvolvem, no indivíduo, competências, habilidades e atitudes que propiciam o pleno desenvolvimento humano conforme as exigências do mundo atual.

O objeto de estudo de Feuerstein é o desenvolvimento da inteligência, com foco na sua dinâmica interacional, entendendo-se que a capacidade de adaptação do ser humano aos desafios e à complexidade do ambiente está em direta proporção à qualidade das experiências mediadoras vivenciadas pelo indivíduo.

A implementação do PEI, como uma ação política, necessitou ser avaliada para que, realmente, fossem reconhecidos os benefícios advindos da aplicação do Programa a alunos do Ensino Médio da Rede Pública Estadual. Para tanto, elaborou-se um Projeto de Pesquisa cujo objetivo geral foi, em primeiro lugar, avaliar a efetividade da aplicação do (PEI), entendido como documento gerador da ampliação da cognição humana, subsidiado, teoricamente, pela TMCE e, metodologicamente, pela EAM. Além disso, buscou-se avaliar o processo de apreensão, significação e transferência de informação por professores e alunos do ensino médio da rede pública estadual, acompanhando a modificabilidade cognitiva dos componentes lógico-simbólicoverbais e perceptivo-espaciais, e a ampliação do raciocínio lógico, analógico e representacional.

A avaliação proposta pela pesquisa compreendeu, basicamente, os três segmentos da escola: o professor, o aluno, o próprio Programa. As ações de pesquisa direcionaram-se para avaliar o grau de aceitação de uma nova estratégia metodológica para respaldar o processo ensino-aprendizagem e para avaliar o grau de modificabilidade advindo da aplicação dos Instrumentos do PEI.

\footnotetext{
${ }^{4}$ Teoria da Modificabilidade Cognitiva Estrutural - TMCE - teoria que fundamenta o PEI, baseada num sistema de crenças - os seres humanos são modificáveis e a pessoa que eu educo é modificável - , fundamentada em dois paradigmas: a modificabilidade, resultante da interatividade, e a adaptabilidade, mudança constante e consciente na resposta a uma nova situação. A TMCE ancora-se na modificabilidade ativa e no contínuo movimento dos recursos do ambiente, envolve o potencial individual e a capacidade do indivíduo para tornar-se modificado e enfoca mudanças estruturais que alteram o curso e a direção do desenvolvimento humano.

${ }^{5}$ Experiência de Aprendizagem Mediada - EAM - interação do ser humano e o seu contexto sociocultural por meio da mediação humana, considerando os três critérios universais, segundo Feuerstein básicos em qualquer experiência de aprendizagem: mediação da intencionalidade / reciprocidade - caracteriza-se pela ação consciente do mediador partilhada pelo mediado; mediação do significado - quando emergem crenças, valores e elementos afetivo-motivacionais na busca de se dar sentido à aprendizagem; mediação da transcendência - responsável pela ampliação do sistema de necessidades do mediado, consiste em generalizar experiências que vão além do momento imediato para outras situações
} 
Para coletar as evidências da modificabilidade advinda do PEI, o estudo comparativo foi escolhido como metodologia de pesquisa e, como instrumentos de coletas de dados, Questionário Socioeconômico e Cultural, Matrizes Progressivas - Escala Geral - Séries A, B, C, D e E (J.C. Raven), Teste PEI, Provas de língua Portuguesa, Matemática, Geografia e História. Foram utilizados, também, questionários e entrevistas com professores e alunos para coleta de opinião sobre o PEI, para acompanhar o planejamento de unidades e de aulas do PEI, observação de aulas a fim de avaliar a modificabilidade na apreensão, significação e transferência de informações.

Os alunos delinearam no Questionário perfis socioeconômicos, hábitos $\mathrm{e}$ dificuldades em seus estudos; no Teste Raven afloraram dificuldades para identificar e compreender progressões numéricas, resolver problemas, usar duas ou mais fontes de informação simultâneas, orientar-se no espaço e no tempo, estabelecer relações, utilizar o raciocínio hipotético-inferencial, adicionar e subtrair, analisar e sintetizar, estabelecer conduta comparativa e reversibilidade da conduta somativa, aplicar a lógica da exclusão, anular opostos.

No teste PEI as dificuldades mais recorrentes foram: codificar ou decodificar várias fontes de informação concomitantemente, analisar e sintetizar, estabelecer semelhanças e diferenças (processo comparativo), usar sistemas de orientação espacial e temporal, entre outros.

Nas Provas de Língua Portuguesa, Matemática, História e Geografia, elaboradas com o foco em competências básicas, operacionais e globais, foram constatadas dificuldades quanto à prontidão cognitiva para estabelecer relações entre conteúdos e contextos e ainda quanto a classificar, seriar, ordenar, compor, decompor, conservar propriedades, fazer antecipações, calcular por estimativa, interpretar, justificar, além de dificuldades para resolver situações-problema, perceber partes diferenciadas, articular-se no espaço, trabalhar sistematicamente, seqüenciar temporalmente, coletar informações com precisão e exatidão, buscar sistematicamente informações, diferenciar dados relevantes e irrelevantes, entre outras.

Apresentando e exercitando competências e habilidades, funções cognitivas e operações mentais, o PEI, além de atender aos princípios da Reforma de Ensino Médio prevista pela LDB 9.394/96, aciona uma quebra de paradigma metodológico com as seguintes características: aluno gerador de informações (crítico, reflexivo, capaz de resolver problemas, autônomo); professor mediador; conhecimento significativo, contextualizado, interdisciplinar, universal; verificação da aprendizagem com foco no processo de aprender a aprender; escola capacitada a construir propostas pedagógicas e caminhos metodológicos; constituição de 
Ambiente Modificador. Isto se faz refletir na capacidade de o aluno compreender a informação, transformá-la e transcender.

\section{O que faz a diferença para o domínio do conhecimento? leitura, biblioteca e letramento informacional}

Persistindo na temática informação, cognição e mediação por reconhecer a força da informação, a importância de sua disseminação para a transformação do ser humano e do seu entorno, sob este título discutiu-se a necessidade do letramento informacional no que tange à apreensão e a construção do conhecimento no Ensino Superior, num contexto de sociedade cognitiva e tecnológica. O trabalho apresenta estudos e pesquisas para avaliar as dificuldades encontradas pelos alunos do Ensino Médio e do Ensino Superior, a partir da análise da relação entre fontes, fluxo e disseminação da informação e do estudo de causas e efeitos da baixa proficiência em leitura como impasse para o acesso ao conhecimento científico com criticidade.

A Universidade, na qualidade de centro autônomo de pesquisa e de criação do saber, é responsável pelo cumprimento da missão do ensino superior pela difusão dos seus valores fundamentais. Para a consecução de suas finalidades educativas, a Universidade busca reforçar o acesso à informação e ao conhecimento - seu papel de instituição social -, procurando implementar ações que contribuam para a formação de cidadãos capazes de atuar, competentemente, no seu contexto social, com o compromisso de construir uma sociedade solidária e ética.

No Brasil, a legislação da Educação Superior é referenciada pela Lei de Diretrizes e Bases da Educação Nacional (LDB), n. ${ }^{\circ}$ 9.394/96, que insere uma nova concepção curricular - "diretrizes curriculares" - tornando-a mais flexível, à medida que confere maior autonomia didático-científica à Universidade, referenciada pelo Sistema Nacional de Avaliação que orienta a demanda, pressionando as instituições universitárias e, por conseqüência, os professores do Ensino Superior a seguir os ditames internacionais.

No entanto, ao se considerar o cenário a ser enfrentado pelos egressos da educação superior, percebe-se uma necessidade crescente de adaptabilidade às novas exigências de uma realidade em permanente mudança, como novos tipos de problema que envolvem novos recursos tecnológicos, quando se torna imprescindível comunicar-se de forma eficaz, 
desenvolvendo o raciocínio crítico, processando e reelaborando a informação recebida, gerando soluções originais, conscientizando-se de seus próprios processos cognitivos.

Entre os estudos avaliativos sobre a proficiência em leitura, destacam-se: Proposta de Avaliação do Exame Nacional do Ensino Médio (ENEM), Proposta do Programa Internacional de Avaliação de Estudantes (PISA) e Estudos e Pesquisas Acadêmicas em Educação e Leitura.

\subsection{Exame Nacional do Ensino Médio (ENEM)}

Os resultados do ENEM, disseminados pelo MEC / SAEB, reforçam a necessidade de estudos e atitudes que otimizem o letramento informacional para a leitura, fortalecendo, assim, no Ensino Superior, o ato de ler. Apresenta, ainda, as diferenças associadas à escola pública e à escola particular, a última com índices mais altos que os da escola pública. Destacam-se as médias associadas à escolaridade do pai e da mãe e à faixa de renda familiar. As médias mais baixas, localizadas na escola pública, estão articuladas à ausência de escolaridade dos pais e às mais baixas faixas de renda familiar de um salário mínimo, inferindo-se que a desigualdade de letramento familiar e conseqüente falta de acesso à informação reflete-se no grau de proficiência cognitiva dos alunos.

Segundo as considerações pedagógicas sobre o ENEM 2001 e 2002,

a ausência do domínio de leitura compreensiva foi a causa principal de situar-se o desempenho dos participantes do ENEM entre insuficiente e regular, visto que a leitura compreensiva é um processo global difuso, intrinsecamente ligado às intenções do participante (leitor), dos professores autores das situações-problema, e ao contexto sociohistórico em que tanto o autor quanto o leitor estão imersos.

Para compreender o texto das situações-problema do ENEM, o participante precisa construir um modelo mental da situação descrita, e isso requer uma série de habilidades anteriores: o reconhecimento de palavras, o entendimento das relações gramaticais e semânticas entre palavras e a integração das idéias e conceitos por meio de inferências.

As inferências intra-sentenciais exigem a associação das informações que se encontram no texto da situação-problema; as inferências 
pragmáticas necessitam de conhecimentos previamente construídos; e as inferências avaliativas exigem posicionamentos pessoais e envolvem valores. A leitura compreensiva é, portanto, um processo de integração e construção de significados. (Relatórios Finais ENEM, 2001 e 2002).

Apesar do empenho do MEC em avaliar e, assim, estimular projetos de intervenção para incrementar o desenvolvimento de competências e habilidades de leitura na Educação Básica, um percentual significativo de estudantes ingressa na educação superior sem o devido desenvolvimento de funções e operações cognitivas para o ato de ler, não podendo o docente universitário avançar no conhecimento específico necessário para a formação profissional. Frente a esta situação, o docente universitário responsabiliza o estudante pelas "conseqüências" da dificuldade para aprender.

\subsection{Programa Internacional de Avaliação de Estudantes (PISA)}

O PISA da Organização para Cooperação e Desenvolvimento Econômico (OECD) foi criado para medir a capacitação dos jovens que estão prestes a concluir a escolaridade compulsória para enfrentar os desafios das sociedades atuais, dependentes de conhecimentos, enfocando habilidades de reflexão, de aplicação de conhecimentos e enfrentamento de desafios.

Segundo autores citados no PISA (2000), um fator importante que permite prever a compreensão em leitura é a quantidade de tempo que os estudantes gastam lendo. Se os estudantes lêem bem, tendem a ler mais e, conseqüentemente, adquirem mais conhecimentos em todos os domínios. Estudantes que têm hábitos deficientes de leitura freqüentemente acham que o material de leitura é difícil demais, portanto, desenvolvem uma atitude negativa em relação à leitura, acabam entrando em um círculo vicioso, uma vez que, por lerem menos, têm menos oportunidade de desenvolver estratégias de compreensão da leitura, e, dessa forma, ficam defasados em todas as disciplinas, já que a leitura é necessária para todas as áreas acadêmicas.

Na tentativa de simular situações autênticas de leitura, a avaliação de leitura do PISA (2000) mede os cinco seguintes aspectos associados à compreensão integral de um texto, seja este contínuo ou não-contínuo: construir uma compreensão geral ampla, recuperar 
informações, desenvolver uma interpretação, refletir sobre o conteúdo de um texto e avaliá-lo e refletir sobre a forma de um texto e avaliá-la.

Em relação aos níveis de proficiência no letramento em leitura, foi registrado que, em parte, as dificuldades são determinadas pela extensão, pela estrutura e pela complexidade do próprio texto. No entanto, notaram também que, na maioria das unidades de leitura, as questões ou instruções variam ao longo da escala de letramento em leitura. Isso significa que, embora a estrutura de um texto contribua para a dificuldade de um item, o que o leitor precisa fazer com o texto, definido pela questão ou instrução, afeta a dificuldade total da tarefa (PISA, 2000).

\subsection{Estudos e Pesquisas Acadêmicas}

No que se refere aos estudos e pesquisas acadêmicas em educação e leitura, profissionais de diferentes áreas de formação e de campos de atuação distintos têm-se preocupado com a questão da leitura, o que, por sua vez, leva-os a repensar a relação entre conhecimento e uso do código alfabético, uso e funções da palavra escrita nas interações sociais - processo de letramento. $O$ interesse pela questão leva-os, também, a refletir sobre quais seriam as práticas de ensino-aprendizagem que possibilitariam ao aluno oportunidades de, mais do que conhecer o código, incrementar a palavra escrita em sua vida, em diferentes situações de interação.

De acordo com Ferreira (2004), o crescimento na quantidade de dissertações de mestrado e de teses defendidas sobre leitura torna-se significativo nas duas últimas décadas, quando já se localizam 227 trabalhos, no período de 1980-1995, e um outro conjunto de 181 pesquisas em apenas cinco anos, de 1996 a 2000, totalizando 431 trabalhos.

Atualmente, o conceito de letramento desmistifica a divisão leitores e não-leitores, questiona as leituras legitimadas pela tradição cultural associada a determinados objetos, formas, lugares e modelos de leitor e traz em seu bojo as pesquisas que tematizam a leitura. $\mathrm{O}$ letramento tem sido, assim, no interior da produção acadêmica, um termo que ora substitui, ora amplia, ora se contrapõe ao conceito de leitura.

$\mathrm{O}$ foco de interesse dos pesquisadores se volta para descrever, entender e recuperar os elementos cognitivos, a dimensão interior desta experiência na relação/atividade do leitor com o material dado a ler. Como se lê? Que habilidades ou competências são necessárias para a leitura? Quais são as dificuldades de leitura? Como processar o entendimento de textos dos mais simples para os mais complexos? (FERREIRA, 2004). 
Um grupo de 104 dissertações de mestrado e teses de doutorado volta-se para instituições importantes na formação de leitores: a escola e a biblioteca. As pesquisas denunciam que a escola e a biblioteca têm falhado em sua função de formar leitores. Falhado pela ausência de atualização desses profissionais na área da leitura, pela falta de um acervo de livros compatível com as necessidades, interesses, expectativas de seus leitores e pela ausência de propostas pedagógicas mais eficientes, dinâmicas e atualizadas para as mudanças da sociedade (FERREIRA, 2000).

$\mathrm{Na}$ década de 80 , as primeiras pesquisas apontam para um leitor mapeado, identificado por sua classe social, econômica, escolar, faixa etária, fatores que interferem na produção dos interesses, das preferências, dos hábitos e gostos pela leitura. Os meninos preferem aventura, as meninas, romances; os alunos mais novos, iniciantes, livros com muitas figuras; os não familiarizados com a cultura escrita ou aqueles de classes mais populares preferem histórias adaptadas e modernizadas dos clássicos.

Outras pesquisas, já na década de 90, olham para esse leitor e buscam conhecê-lo pela sua história de leitura, pelas experiências vividas no interior da escola e fora dela. Relativiza-se, neste caso, a responsabilidade da escola e da biblioteca que oferecem alguns modos de ler e algumas habilidades. A leitura passa a ser entendida como uma prática social e não apenas escolarizada. As pesquisas buscavam imagens e representações construídas socialmente pelos sujeitos acerca da leitura, através de depoimentos, relatos, histórias de vida e de leitura, estudos de caso. Recentemente, alguns trabalhos voltam-se às práticas sociais de leitura ligadas a determinadas comunidades de leitores: leitura feminina de romances sentimentais de massa, como as leitoras da série Sabrina, leitores de Role Plaing Games (RPG), leitores de assentamentos, leitores universitários.

Partindo de um modelo de leitor ideal (aquele que lê muito, sistemática e freqüentemente, obras de literatura normalmente clássicas e legitimadas pela academia, aquele que assina e lê jornais de grande circulação e revistas especializadas), os trabalhos denunciam a ausência de leitura por parte do professor. Quanto ao professor em formação, os pesquisadores mostram-se preocupados em equacionar os currículos dos cursos de graduação, bem como a inclusão de disciplinas que possam assegurar a produção de "novos" conhecimentos, ainda durante seu processo de formação inicial, capacitando esse formando para que ele possa contribuir com a importante função social da escola - formar leitores. 


\subsection{Reflexões}

Que lugar é reservado ao leitor para o fortalecimento do ato de ler e para o desenvolvimento de habilidades de leitura nos cursos universitários? Formam-se leitores ou, ao contrário, instala-se ou reforça-se o "desgosto" pela leitura?

Que prática ou práticas pedagógicas desenvolvem habilidades para investigar e diagnosticar os problemas de informação que afetam o usuário quanto à aquisição do conhecimento? Como objetivar a formação de um "gestor da informação" com atitude investigativa?

Lecionando, no semestre 2005.2, em três turmas de Graduação em Biblioteconomia e em Arquivologia, após aplicação de questionário a 60 alunos, o perfil da clientela caracterizou-se por estudantes que chegaram ao Curso de Biblioteconomia e de Arquivologia por acaso, por oportunidade, oriundos do Ensino Médio de Escola Pública, com escolaridade dos pais focada no Ensino Médio, estudantes que declaram gostar de ler e não ter dificuldade de leitura, contudo, isso não está refletido nos dados coletados em relação à freqüência de leitura, no tempo dedicado à leitura, no que costumam ler, na dificuldade de leitura registrada - "organizar dados e informações para argumentar" - e nas sugestões apresentadas para melhorar o grau de proficiência em leitura.

Infere-se, portanto, que as turmas consultadas não cheguem, com facilidade, à leitura de textos científicos complexos, o que é testemunhado, cotidianamente, durante as aulas, em atividades de leitura, de apresentações orais e escritas, e, entre outros aspectos, não dominam a expressão oral e escrita da língua, exibem dificuldades na construção de argumentos, em resumir e sintetizar, em detectar e resolver situações-problema, estabelecer relações, tudo isso aliado à falta de técnicas alternativas para estudar, além de demonstrar baixa estima quanto às próprias potencialidades e habilidades. As evidências mostram a necessidade do desenvolvimento de esquemas intelectuais necessários à abstração e estratégias de aprendizagem que subsidie o aluno em solucionar situações-problema.

\section{Aportes das teorias cognitivas ao processo de tratamento da informação}

A intenção deste trabalho foi analisar a relação da Ciência da Informação, Biblioteconiomia e Arquivologia, com os estudos da cognição humana, na perspectiva 
interdisciplinar e transdisciplinar da construção do conhecimento. Reflete-se sobre a representação e organização do conhecimento em sistemas de indexação e recuperação da informação. Analisa-se a evolução e a relação das ciências cognitivas com a indexação, fato este observado quando se aplicam os estudos cognitivos às ferramentas de indexação e recuperação e na relação das pessoas que participam nestes processos.

Neste novo contexto, emerge como elemento fundamental a inclusão das teorias cognitivas no processo de ensino e aprendizagem nos cursos de graduação, mediante a necessidade do profissional de captar e interiorizar conhecimentos em seu núcleo de capacidades e competências permitindo-lhe melhorar sua atuação e desempenho mediante o desenvolvimento dos estudos e pesquisas no campo da informação.

Embora haja um consenso de que, no âmbito da CI, a mediação se dá no processo de interação do profissional com o usuário, ou seja, no momento da comunicação e da transferência da informação, na verdade, os elementos que compõem a mediação e que vão permitir a consonância de objetivos entre o que busca o usuário e o que lhe oferta o profissional acontece bem antes da busca, mediante um processo dialógico em que o profissional se antecipa ao desejo do usuário e organiza o estoque de informação, dialogando com este usuário potencial. Assim, os elementos que compõem a mediação são os que vão permitir a harmonia de objetivos entre o que busca o usuário e o que o profissional oferece.

É evidente que o profissional se norteia por alguns parâmetros, tais como: conhecer, em tese, as necessidades de seu usuário; categorizar e representar de modo físico e temático o estoque de conhecimento acumulado; construir instrumentos de recuperação desta representação e, ao tecer o instrumento que, de modo simbólico, mas significativo, espelhará o estoque do conhecimento que está tratando, o profissional também pressupõe a trajetória lógica com a qual o usuário organiza seu pensamento para pesquisar a informação.

A cognição é um conhecimento relevante para que o profissional da informação possa compreender e delinear a trajetória lógica do usuário no processo de busca da informação e da construção dos meandros da cognição na apreensão do conhecimento.

O construtivismo representa a posição mais desenvolvida e sustentada das vanguardas pedagógicas contemporâneas e alcançou um consenso emergente entre a comunidade acadêmica pedagógica e psicológica. Sem dúvida, o construtivismo pedagógico tem seus pilares nos mais importantes avanços dos estudos da epistemologia e psicologia durante o século XX, ao considerar o conhecimento como uma construção do ser humano e não como uma cópia da realidade e ao considerar a ciência como construtora e não como "descobridora" de realidades. 
Um dos maiores aportes do construtivismo é o papel ativo do sujeito no processo de conceitualização e o de reconhecer a existência de elementos pessoais, matizes e acepções na representação individual. Para fundamentar a reflexão no tema considerado neste artigo, buscaram-se subsídios teóricos nos seguintes estudiosos: Piaget, Vygostsky, Paulo Freire e Reuven Feuerstein.

\subsection{Subsídios Teóricos}

Segundo Piaget (1971), a estrutura cognitiva é construída em etapas e cada etapa incorpora as anteriores, dando-se a construção do conhecimento pela ação recíproca e interativa do sujeito com os objetos (meio). A organização da realidade dá-se por meio do pensamento estruturado, que se expressa mediante o processo de adaptação. Assim, a estrutura mental e o conhecimento são construídos em uma relação dialética entre a maturação biológica e o ambiente.

Para entender o processo de apreensão da realidade por meio da estrutura cognitiva, que organiza os estímulos do mundo, Piaget (1971) desenvolveu e definiu os dois pilares de sua teoria: a assimilação e a acomodação. $\mathrm{O}$ conceito de assimilação diz respeito à capacidade de a estrutura cognitiva do indivíduo atuar no ambiente. $\mathrm{O}$ organismo assimila a realidade de acordo com a capacidade de sua estrutura cognitiva interna. Em contrapartida, a estrutura cognitiva é mobilizada e modificada em função da realidade, acomodando-se a ela. A adaptação justifica-se como um estado de equilíbrio entre a acomodação e a assimilação.

A abordagem sócio-histórica de Vigotsky (1991) baseia-se na idéia central de que o ser humano se desenvolve pela interação social, quando o desenvolvimento cognitivo mantém estreita relação com a aprendizagem. A aprendizagem, quando significativa, estimula e desencadeia o avanço para um nível de maior complexidade que, por sua vez, serve de base para novas aprendizagens.

Vigotsky formulou os conceitos de zona de desenvolvimento real, zona de desenvolvimento proximal e zona de desenvolvimento potencial. A zona de desenvolvimento real é o nível de desenvolvimento das funções mentais do indivíduo que se estabeleceram como resultado de certos ciclos de desenvolvimento já completados, ou de um processo de desenvolvimento específico. A zona de desenvolvimento proximal é a distância entre o nível de desenvolvimento real, que se costuma determinar com a solução de problemas de forma independente, e a zona de desenvolvimento potencial determinado, com a solução de 
problemas sob a orientação de outro indivíduo ou em colaboração com companheiros mais capazes.

Todo ser humano, inserido em uma realidade sócio-histórica, somente adquire a condição humana se for, em sua relação com o mundo, mediado por instrumento de sua cultura - signo, palavra, símbolo. O conhecimento é, portanto, uma produção cultural, diretamente relacionada com a linguagem e com a interação social. A mediação é a ação que se interpõe entre sujeito e objeto de aprendizagem, sendo a palavra de fundamental importância.

A obra de Paulo Freire (1980), se constitui em uma tentativa de recuperar e proporcionar conceitos e instrumentos metodológicos do estruturalismo genético e da razão dialética, mostrando sua aplicabilidade ao processo pedagógico. No conjunto de sua obra, podem ser destacados alguns elementos ontológico-epistemológicos, entre eles o conceito de "educação dialógica" versus "educação bancária". Na "educação bancária" duas estruturas se confrontam - a do educador que sabe e comunica e a do educando que não sabe e aprende - e na educação dialógica, dois processos de estruturação gnoseológica interagem, um ensinando/aprendendo com o outro e ambos construindo o conhecimento do mundo.

Freire $(1979,2002)$ ressalta a importância e a necessidade de se entender a existência humana a partir de sua substancialidade, ou seja, o reconhecimento de todos os homens como verdadeiros sujeitos históricos. Os atributos dos seres humanos não podem, assim, sobrepujar o reconhecimento da existência humana: a sua presença no mundo como sujeito.

A Teoria da Modificabilidade Cognitiva Estrutural (TMCE) fundamenta-se no enfoque ativo e otimista da capacidade de modificabilidade do ser humano, requerida para as mudanças que a sociedade atual exige, capacidade que possibilita a integração. Feuerstein (1980) averigua como o sujeito chega à solução do problema, empregando a analogia do computador - entrada, processo e saída - e propõe o mapa cognitivo como ferramenta de análise do ato mental. Esse mapa demonstra como o sujeito aprende e, o mais importante, permite-lhe aprender a aprender. A teoria tem como um dos aportes conceituais centrais o pressuposto de que o ser humano é dotado de uma mente plástica, flexível, aberta à mudança, assim como de um potencial e de uma propensão natural para a aprendizagem.

Feuerstein (1980) explica a aprendizagem humana, não só pela integridade biológica dos genes e cromossomos ou pela simples exposição direta a objetos, acontecimentos, atitudes e situações, mas emerge de uma relação indivíduo-meio, que é mediatizada por outro indivíduo mais experiente, cujas práticas e crenças culturais são transmitidas, promovendo 
zonas mais amplas de desenvolvimento crítico e criativo - desenvolvimento de processos psicológicos superiores - rumo à autonomia cognitiva, portanto decorre de uma aprendizagem mediada.

Para explicar como a interação humana impulsiona o desenvolvimento da estrutura cognitiva e fomenta a capacidade humana à modificabilidade Feuerstein desenvolve o aporte conceitual central de sua teoria: a Experiência de Aprendizagem Mediada (EAM), ressaltando que toda interação humana se viabiliza pela comunicação. Desse modo, a EAM tem seu foco não no conteúdo das informações, mas na estratégia metodológica dialógica intencional quando emissor e receptor são os responsáveis pelo conhecimento construído, interagindo constantemente, dando importância à troca de impressões, aos sentimentos sobre o mundo e ao intercâmbio de formas de compreensão da realidade.

Segundo Morin (2000), um conhecimento pertinente deve enfrentar a complexidade. Complexus significa "o que foi tecido junto". Há complexidade quando elementos diferentes, constitutivos do todo, são inseparáveis (como o econômico, o político, o sociológico, o psicológico, o afetivo, o mitológico), há um tecido interdependente, interativo e interretroativo do objeto de conhecimento com seu contexto - as partes e o todo, o todo e as partes, as partes entre si. A complexidade, portanto, é a união da unidade com a multiplicidade, sabendo-se, de antemão, que sempre haverá a incerteza no pensamento complexo, o que permite escapar do dogmatismo que reina nos pensamentos não complexos.

Cremos ver a realidade, mas na verdade vemos o que o paradigma solicita que seja visto, ocultando-se o que ele impõe que não se veja. O mundo como o vemos é, pois, fruto do que se pode chamar, segundo Morin (1986), de uma dialógica de ordem e desordem. Dialógica por se tratar de duas noções totalmente heterogêneas - que se rechaçam mutuamente. É preciso, pois, trabalhar com a desordem e com a incerteza e perceber que trabalhar com a desordem e a incerteza não significa deixar-se ser submerso por elas. $\mathrm{O}$ verdadeiro pensamento é o que olha de frente, enfrenta a desordem e a incerteza.

Para Morin (1986) a capacidade de aprender está ligada ao desenvolvimento das competências inatas do indivíduo em adquirir conhecimentos, associadas às influências e estímulos externos, da cultura e o ato de conhecer está presente nas ações biológicas, cerebrais, espirituais, culturais, lingüísticas, sociais políticas e históricas. Desse modo, o ser condiciona o conhecer, que ao mesmo tempo condiciona o ser. 


\subsection{As Teorias Cognitivas no Tratamento da Informação}

A codificação e decodificação de contexto permitem ao sujeito compreender seu lugar na construção do conhecimento, num movimento de representação e análise crítica da situação codificada, o que propicia sua mobilização em novos contextos, possibilitando a intervenção na realidade, constituindo-se competência crítico-analítica de apreender uma representação da realidade para discussão, o que possibilita a construção de um novo conhecimento. Desse modo, chega-se ao campo epistemológico da interdisciplinaridade, tendo como base a contextualização (MORAES et al., 2004).

Exige-se das pessoas que trabalham com a indexação diferentes competências objetivando a adequada recuperação de informações contidas em documentos, sejam eles impressos ou eletrônicos. Tais competências vão desde o domínio de técnicas e métodos relativamente simples até a proficiência de linguagens complexas de indexação. Esse é um aspecto importante das atividades de informação na relação com usuários. (MITTERMEYER, 2003, p.28).

A CI, na tentativa de disseminar o conhecimento, sempre enfatizou o atributo / conceito como elemento básico de representação. Para tanto, fundamentou-se, inicialmente, em princípios filosóficos acompanhando a organização e estruturação das ciências. Em sua essência, a CI estuda o fenômeno informacional, com o objetivo de orientar a disseminação da informação por meio de sistemas de recuperação da informação. Para estabelecer a relação usuário / conhecimento, a CI se apropria da categoria conceito como um atributo essencial na construção da trajetória a ser percorrida pelo usuário.

Nesta perspectiva, as teorias, métodos e procedimentos que compõem o "corpus" da Ciência da Informação só têm significado quando o usuário encontra a "informação útil”, ou seja, pertinente à solução do seu problema.

Lancaster esclarece que a indexação de assunto e a recuperação da informação são faces de uma mesma moeda, na medida que se faz a indexação para que a recuperação se torne possível em um momento posterior. É neste processo de construção do método de indexação e de desconstrução deste caminho no momento da busca, que as teorias de cognição se fazem necessárias.

De modo mais evidente, os termos atribuídos pelo indexador servem como pontos de acesso mediante os quais um item é localizado e recuperado, durante uma busca por assunto num índice publicado ou numa base de dados eletrônica. (LANCASTER, 2004, p.6). 
A indexação temática, como uma técnica de processamento da informação, constitui-se num exercício intelectual de apreensão e representação do conhecimento contido em algum tipo de fonte informacional, que se completa, quando, em algum momento, o usuário recupera a informação necessária à consecução de sua ação. Para construir/desconstruir o método de indexação utilizado, o usuário elabora a estratégia de busca.

Além disso, conforme destaca Lancaster (2004, p.10), Guinchat e Menou (1994, p.122) e vários outros autores, a indexação de conteúdos é destinada a um público-usuário determinado e, deste modo, o indexador precisa conhecer os interesses destes usuários e, na escolha dos termos considerar os vários aspectos. Por isso, a mesma fonte de informação pode estar indexada de diferentes modos, focando interesses diversificados dos usuários.

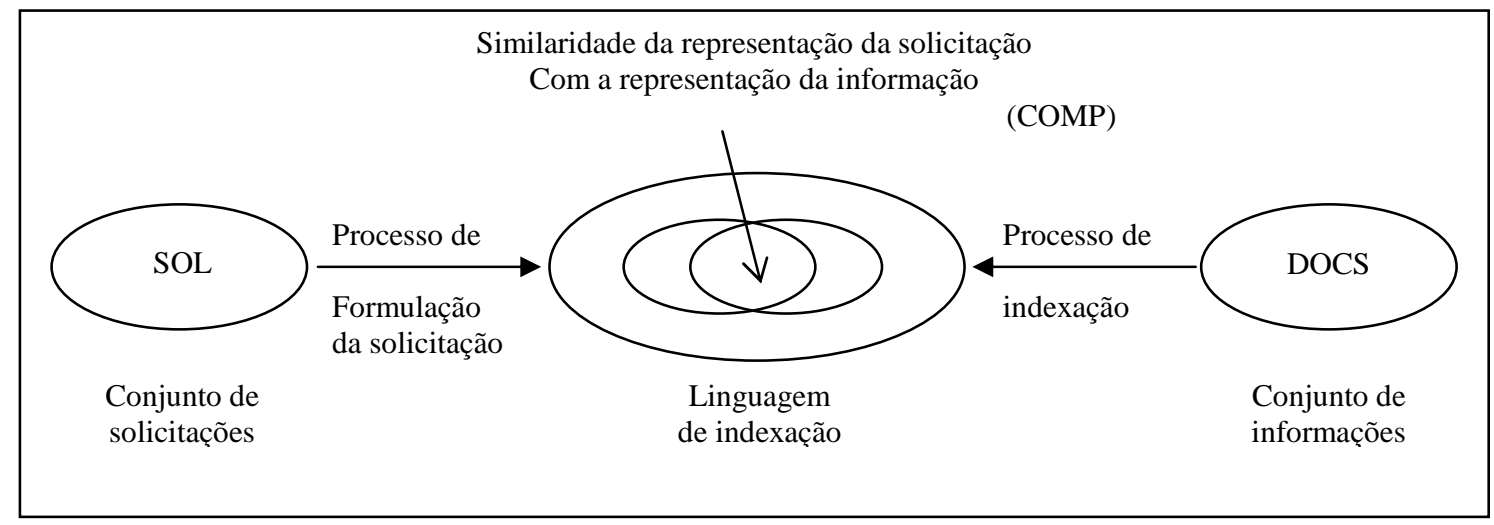

Figura 2. Esquema funcional de um SRI. (KURAMOTO, 2006, p. 120).

A figura acima ilustra particularmente a existência da convergência de trajetórias cognitivas entre quem elabora o esquema de indexação e o sujeito que o codifica/decodifica no momento da busca da informação, demonstrando que a recuperação só se torna possível quando as estratégias de indexação e de busca se aproximam. $\mathrm{O}$ uso de instrumentos normatizadores, como por exemplo, os tesauros pode reduzir o grau de incerteza deste processo.

Todos estes fatores estão estreitamente relacionados às categorias cognição / conhecimento, elementos que permeiam o curso das ações indexação de conteúdo / recuperação da informação, na medida que embasam a trajetória lógica do indexador na construção do instrumento de busca e do usuário na elaboração da estratégia.

Diante do exposto, a transferência e a aplicabilidade dos princípios do estruturalismo genético de Piaget, da teoria sócio-histórica de Vigotsky, da TMCE e da EAM de Feuerstein, 
e os enfoques de consciência e autonomia de Paulo Freire e a Teoria da Complexidade de Morin merecem destaque emergindo à sua representatividade como facilitadores das condições da estrutura lógica dos que lidam com informação e educação, os quais devem ser co-responsáveis pelo desenvolvimento de competências características dessa sociedade em mudança, destacando-se entre elas as competências cognitivas e informacionais, temas em discussão no contexto mundial.

Ressaltou-se, portanto, as múltiplas facetas da Informação, Mediação e Cognição e as evidências mostram a necessidade do desenvolvimento de esquemas intelectuais necessários à abstração e estratégias de aprendizagem que subsidiem o fortalecimento dos processos de leitura, preparando o leitor crítico que conseqüentemente incrementará a disseminação da informação e a construção de novos conhecimentos.

O desafio que se coloca, neste início de século, diante do uso extensivo das tecnologias da informação e da viabilização de condições para que as pessoas compartilhem os significados que podem ser atribuídos às informações - a construção de conhecimento significativo -, é o de que as instituições responsáveis pela disseminação de conteúdos transformem-se em comunidades dedicadas à construção coletiva de significados, passem de meros intermediários do processo de aquisição da informação à construtores do conhecimento.

Para tanto, delineia-se uma mudança de paradigma, um modelo centrado no sujeito/usuário voltado para o aprendizado como processo contínuo de internalização de fundamentos conceituais, atitudinais, comportamentais e de habilidades necessárias à compreensão e interação permanente com o universo informacional e sua dinâmica Information Literacy -, quando professores e bibliotecários integram-se em prol do fortalecimento da apreensão e da construção do conhecimento científico.

Espera-se que com o exposto tenha-se contribuído para alertar que o tempo de vida humana alonga-se e o tempo de vida das tecnologias reduz-se. Novas necessidades da sociedade implicam novas atitudes. A sociedade do conhecimento requer: mentes que pensem e que se antecipem, pessoas autônomas no pensar, no sentir e no fazer, sujeitos que tenham a capacidade de julgar as situações com base em idéias e elementos. Necessita-se de ferramentas cognitivas para compreender e anunciar realidades complexas e com elas interagir. 


\section{Referências}

BEYER, Hugo Otto. O fazer psicopedagógico: a abordagem de Reuven Feuerstein, a partir de Piaget e Vygotsky. Porto Alegre: Mediação, 1996.

BLOOM, Benjamin S. (ed.). Taxionomia de Objetivos Educacionais: domínio cognitivo 1. Tradução de Flávia Maria Sant’Anna. 7. ed. Porto Alegre: Editora Globo, 1979.

BRASIL. Ministério da Educação. Secretaria de Educação Média e Tecnológica. Instituto Nacional de Exames e Pesquisas Educacionais Anísio Teixeira. Exame Nacional do Ensino Médio: Documento Básico. Brasília, 1998.

BRASIL. Ministério da Educação. Secretaria de Educação Média e Tecnológica. Parâmetros curriculares nacionais - ensino médio: bases legais. Brasília, 1999.

BRASIL. Ministério da Educação. Secretaria de Educação Média e Tecnológica. Exame Nacional do Ensino Médio: Relatório Pedagógico 2002. Brasília, 2002.

BRASIL. Ministério da Educação. Secretaria de Educação Média e Tecnológica. Exame Nacional do Ensino Médio: Relatório Pedagógico 2003. Brasília, 2003.

BRASIL. Ministério da Educação. Secretaria de Educação Média e Tecnológica. Instituto Nacional de Exames e Pesquisas Educacionais Anísio Teixeira. Exame Nacional do Ensino Médio: Sumário Executo: Primeiros Resultados. Brasília, 2003.

BRASIL. Ministério da Educação. Secretaria de Educação Média e Tecnológica. Instituto Nacional de Exames e Pesquisas Educacionais Anísio Teixeira. Exame Nacional do Ensino Médio: Informativo ENEM 2005. Brasília, 2005.

DUARTE, Newton. A Individualidade para SI: contribuição a uma teoria histórico-social da formação do indivíduo. Campinas, SP: Editora Autores Associados, 1993.

FERREIRA, N.S. A. A pesquisa sobre leitura no Brasil, 1980-2000. Campinas: Komeid: Arte e Escrita, 2001. 
Leitura como objeto de investigação. Revista da FAEEBA - Educação e

Contemporaneidade. Salvador, v. 13, n. 21, p. 13-22. jan./jun., 2004.

FEUERSTEIN, Reuven. Instrumental enrichment: an Intervention Program for Cognitive Modifiability. Baltimore, Md.: University. Park Press, 1980. 436 p.

FREIRE, Paulo. Educação e mudança. Rio de Janeiro: Paz \& Terra, 1979.

FREIRE, Paulo. Conscientização. São Paulo: Moraes, 1980.

FREIRE, Paulo. Pedagogia do oprimido. 32. ed. Rio de Janeiro: Paz \& Terra, 2002.

GUINCHAT, C.; MENOU, Michel. Introdução geral às ciências e técnicas da informação e documentação. Brasília: IBICT, 1994.

KIRSCH. et al. Letramento para mudar: avaliação do letramento em leitura: resultados do PISA 2000. Tradução B \& C Revisão de Textos. São Paulo: Moderna, 2004.

KURAMOTO, Hélio. Sintagmas nominais: uma nova abordagem no processo de indexação. In: NAVES, M. M. L.; KURAMOTO, H. (Org.). Organização da informação: princípios e tendências. Brasília: Briquet Lemos, 2006. p.117-137.

LANCASTER, F. W. Indexação e resumos: teoria e prática. 2. ed. Brasília: Briquet de Lemos Livros, 2004.

MITTERMEYER, Diane. Unique aspects of LIS marketing: the third party theory. In: GUPTA, Dinesh K.; JAMBHEKAR, Ashok. An integrated approch to services marketing: a book of reading on marketing of library and information services. Mumbai: Allied Publishers Private, 2003. p.27-41.

MORAES. et al. Sociologia. In: BRASIL. Ministério da Educação, Secretaria de Educação Básica - SEB, Departamento de Políticas de Ensino Médio. Orientações Curriculares do Ensino Médio, Brasília, 2004.

MORIN, Edgard. Os sete saberes necessários à educação do futuro. Tradução de Catarina Eleonora F. da Silva e Jeanne Sawaya. Revisão técnica Edgard de Assis Carvalho [São Paulo/Brasília: Cortez/Unesco, 2000]. 
MORIN, Edgard. O método I: o conhecimento do conhecimento [Lisboa: Europa-América, 1986].

PIAGET, Jean. A epistemologia genética. Petrópolis: Vozes, 1971.

URDANETA, Iraset Paez. Gestión de la Inteligencia, aprendizaje tecnológico y modernización del trabajo informacional. Retos y Oportunidades. In: Instituto de Estudios del Conocimiento de la Universidad Simon Bolívar e Consejo Nacional de Investigaciones Científicas y Tecnológicas. Caracas, Venezuela, 1992.

VARELA, Aida Varela. Informação e Autonomia: a mediação segundo Feuerstein. São Paulo: Editora Senac, 2007. 368 p.

VARELA, Ainda. Informação e Construção da Cidadania. Brasília: Thesaurus, 2007. $144 \mathrm{p}$.

VIGOTSKY, L. S. A formação social da mente. São Paulo: Martins Fontes, 1991. 